\title{
Preparation of Glycidol via Dehydrohalogenation of 3-Chloro-1,2-popanediol Using Bipolar Membrane Electrodialysis
}

Andrzej Milewski ${ }^{1 *}$, Dymitr Czechowicz ${ }^{2}$, Agata Jakóbik-Kolon ${ }^{1}$, Piotr Dydo ${ }^{1}$

1. Department of Inorganic, Analytical Chemistry and Electrochemistry, Faculty of Chemistry, Silesian University of Technology, 6 Krzywoustego St., 44-100 Gliwice, Poland 2. Department of Chemical Organic Technology and Petrochemistry, Faculty of Chemistry, Silesian University of Technology, 4 Krzywoustego St., 44-100 Gliwice, Poland

\footnotetext{
*Corresponding author

E-mail: Andrzej.Milewski@polsl.pl
}

5 pages 


\section{Experimental}

\section{Materials and methods}

Materials: Reagents and standards such as 3-chloro-1,2-propanediol ( $\alpha$-monochlorohydrin or 3-MCH, >98\%, Acros Organics), glycidol (GD, $\geq 99 \%$, Acros Organics), glycerol (GL, >99\%, Honeywell Specialty Chemicals), triglycerol (technical $\geq 60 \%$, Sigma-Aldrich) and potassium chloride (Avantor Performance Materials, Poland S.A) were used without purification. The solvents: acetonitrile and anhydrous methanol were purchased from Acros Organics and used as received; deionized water $(0.095 \mu \mathrm{S} / \mathrm{cm})$ was obtained from an Elix Millipore system.

Nuclear Magnetic Resonance (NMR): ${ }^{1} \mathrm{H}$ NMR spectra were recorded in $\mathrm{D}_{2} \mathrm{O}$ on a Varian 400 spectrometer, operating at $400 \mathrm{MHz}$, in which 3-(trimethylsilyl)propionic-2,2,3,3- $\mathrm{d}_{4}$ acid (TMSP- $\mathrm{d}_{4}$, sodium salt $>98 \%$, Acros Organics) was used as the calibration standard.

High-Performance Liquid Chromatography (HPLC): The samples $\left(0.1 \mathrm{~cm}^{3}\right)$ were directly diluted with $1 \mathrm{~cm}^{3}$ acetonitrile and analyzed by HPLC (Thermo Scientific) using a LiChrosorb ${ }^{\circledR}$ Diol-5 column $(25 \mathrm{~cm} \times 4.0 \mathrm{~mm}$, particle size: $5 \mu \mathrm{m})$ with an RI detector K2301 KNAUER.

Gas Chromatography-Mass Spectrometry (GC-MS): The samples were analyzed using an Agilent GC-MS (Agilent 7890/5975C) equipped with a capillary column (Zebron ZB-5HT, 30 $\mathrm{m} \times 0.25 \mathrm{~mm} \times 0.25 \mu \mathrm{m})$. Injector $-300^{\circ} \mathrm{C}$, injection volume $-0.2 \mu \mathrm{L}$, split $50: 1$, oven temperature program $-100^{\circ} \mathrm{C}(3 \mathrm{~min}), 10^{\circ} \mathrm{C} / \mathrm{min}$ to $300^{\circ} \mathrm{C}(17 \mathrm{~min})$, carrier gas - helium $(0.6$ $\left.\mathrm{cm}^{3} / \mathrm{min}\right)$, GC-MS interface temperature $-300^{\circ} \mathrm{C}$.

Gas Chromatography with Flame Ionization Detector (GC-FID): The samples were analyzed using the gas chromatograph (Agilent 7890) equipped with a capillary column (Zebron ZB5HT, $30 \mathrm{~m} \times 0.25 \mathrm{~mm} \times 0.25 \mu \mathrm{m})$. Injector $-300^{\circ} \mathrm{C}$, volume of injection $-0.2 \mu \mathrm{L}$, split 50:1, oven temperature program $-100^{\circ} \mathrm{C}(3 \mathrm{~min}), 10^{\circ} \mathrm{C} / \mathrm{min}$ to $300^{\circ} \mathrm{C}(17 \mathrm{~min})$, carrier gas - helium 
$\left(1.1 \mathrm{~cm}^{3} / \mathrm{min}\right), \mathrm{GC}-\mathrm{FID}$ interface temperature $-320^{\circ} \mathrm{C}$. The concentration of compounds in the post-reaction mixture was calculated by normalization to $100 \%$ of the chromatographically determined shares of organic compounds in the water-free final sample. The relative response factor of these compounds was estimated based on Effective Carbon Number concept ${ }^{1}$

Fourier Transform Infrared (FTIR) spectroscopy from Attenuated Total Reflectance (ATR): The FTIR spectra of dried membranes were recorded at room temperature using a Thermo Scientific $^{\mathrm{TM}}$ Nicolet $^{\mathrm{TM}}$ iS ${ }^{\mathrm{TM}} 5$ FT-IR Spectrometer with Spectrum software version 6.3.2, equipped with a Nicolet 6700 Thermo Scientific ${ }^{\mathrm{TM}}$ iD7 ATR (attenuated total reflectance) sampling device containing a diamond/ZnSe crystal. The spectra were acquired from 4000 to $650 \mathrm{~cm}^{-1}$ at a scan speed of $0.2 \mathrm{~cm} / \mathrm{s}$ with $8 \times 16(128 \mathrm{scans})$ an a resolution of $4 \mathrm{~cm}^{-1}$. A background spectrum was scanned under the same instrumental conditions before each series of measurements.

Inductively Coupled Plasma - Mass Spectrometry (ICP-MS, Varian 810 MS). The samples were dissolved in deionized water to obtain an organic compound concentration below $0.5 \%$ and analyzed by measuring the ${ }^{35} \mathrm{Cl}$ isotope signal and using a calibration curve $(\mathrm{Cl}$ in the range of $20-800 \mu \mathrm{g} / \mathrm{L})$.

Ion-Chromatography (IC): Concentrations of chloride ions were determined using an ionchromatography system (ICS-5000, Thermo Dionex, USA) equipped with AS-19 anionexchange and CS-16 cation-exchange columns operated in a suppressed conductivity mode.

\section{Data analysis}

The conversion of 3-MCH $\left(\alpha_{M C H}\right)$ was calculated as follows:

$$
\alpha_{M C H}=100 \square \frac{m_{0}-m}{m_{0}}[\%]
$$


where $m_{0}[\mathrm{~g}]-$ mass of $3-\mathrm{MCH}$ in solution before the BP-ED process; $m$ [g] - mass of 3 -MCH in solution after the BP-ED process

The yield of glycidol $\left(Y_{G D}\right)$ or glycerol $\left(Y_{G L}\right)$ from 3-MCH was calculated as follows:

$Y_{G D}=100 \square \frac{m_{G D}}{m_{t G D}}[\%]$

$Y_{G L}=100 \square \frac{m_{G L}}{m_{t G L}}[\%]$

where $m_{G D}$ or $m_{G L}[\mathrm{~g}]-$ GD or GL mass, $m_{t G D}$ and $m_{t G L}[\mathrm{~g}]-$ the theoretical mass of GD or GL.

The selectivity of glycidol formation $\left(S_{G D}\right)$ was calculated as follows:

$S_{G D}=100 \square \frac{n_{G D}}{\left(n_{0 M C H}-n_{M C H}\right)}[\%]$

where $n_{G D}, n_{M C H}$ - the number of GD moles and 3-MCH moles, $n_{0 M C H}-$ initial number of 3MCH moles.

The current efficiency (CE) was calculated as follows:

$C E=100 \square \frac{F_{n} \cdot n_{G D}}{Q}[\%]$

where $F_{n}$ - Faraday's constant: $26.8 \frac{A \cdot h}{\mathrm{~mol}}, n_{G D}$ - number of GD moles, Q [Ah] - electric charge The formation rate of glycidol $(r)$ was defined as follows:

$r=\frac{m_{G D}}{\mathrm{t} \cdot S}\left[\mathrm{~g} / \mathrm{m}^{2} \cdot \mathrm{h}\right]$

where $m_{G D}[\mathrm{~g}]$ - mass of glycidol, $t[\mathrm{~h}]$ - time, $S\left[\mathrm{~m}^{2}\right]$ - an active membrane area. 
The electric energy consumption $(P)$ was calculated as follows:

$P=\frac{U \square Q}{m_{G D}}[k W h / k g]$

Where $\mathrm{U}[\mathrm{V}]$ - electric potential or voltage, $\mathrm{Q}[\mathrm{Ah}]$ - electric charge, $\mathrm{m}_{\mathrm{GD}}[\mathrm{kg}]$ - mass of glycidol.

Apparatus and experimental condition

Experiments were carried out on plate and frame electrodialysis cells, equipped with Ptcoated titanium electrodes, with an active membrane area of $63.6 \mathrm{~cm}^{2}$. In all experiments, Ralex (MEGA, Czech Republic) AM-PP anion-exchange membranes (AEM), CM-PP cationexchange membranes (CEM) and bipolar-membranes (BPM) were used.. These membranes were mounted in a plate and frame type ED stack with an intermebrane distance of $5 \mathrm{~mm}$. The electrode rinse solution (chamber 1) contained $0.25 \mathrm{M} \mathrm{K}_{2} \mathrm{SO}_{4}$ whilst process solutions (chambers 2 and 3) contained $0.1 \mathrm{M} \mathrm{KCl}$ as a base electrolyte. Additionally, the dehydrohalogenation compartment solution (chamber 3) contained 3-MCH at varying concentrations. The electrode and process solution volumes were $250 \mathrm{~cm}^{3}$ and $100 \mathrm{~cm}^{3}$, respectively. During electrodialysis, these solutions were recirculated through the ED stack at a linear flow velocity of $100 \mathrm{~cm} / \mathrm{min}$. Periodically, samples of the process solutions were collected and analyzed.

\section{Reference:}

(1) Scanlon, J. T.; Willis, D. E. Calculation of Flame Ionization Detector Relative Response Factors Using the Effective Carbon Number Concept. J. Chromatogr. Sci. 1985, 23, 333340. 